\title{
Effect of model resolution on a regional climate model simulation over southeast Australia
}

\author{
Jason P. Evans ${ }^{1, *}$, M. F. McCabe ${ }^{2,3}$ \\ ${ }^{1}$ Climate Change Research Centre and ${ }^{2}$ School of Civil and Environmental Engineering, University of New South Wales, \\ Sydney 2052, Australia \\ ${ }^{3}$ Water Desalination and Reuse Center, Biological and Environmental Sciences and Engineering Division, \\ King Abdullah University of Science and Technology, Thuwal, Saudi Arabia
}

\begin{abstract}
Dynamically downscaling climate projections from global climate models (GCMs) for use in impacts and adaptation research has become a common practice in recent years. In this study, the CSIRO Mk3.5 GCM is downscaled using the Weather Research and Forecasting (WRF) regional climate model (RCM) to medium $(50 \mathrm{~km})$ and high $(10 \mathrm{~km})$ resolution over southeast Australia. The influence of model resolution on the present-day (1985 to 2009) modelled regional climate and projected future (2075 to 2099) changes are examined for both mean climate and extreme precipitation characteristics. Increasing model resolution tended to improve the simulation of present day climate, with larger improvements in areas affected by mountains and coastlines. Examination of circumstances under which increasing the resolution decreased performance revealed an error in the GCM circulation, the effects of which had been masked by the coarse GCM topography. Resolution modifications to projected changes were largest in regions with strong topographic and coastline influences, and can be large enough to change the sign of the climate change projected by the GCM. Known physical mechanisms for these changes included orographic uplift and low-level blocking of air-masses caused by mountains. In terms of precipitation extremes, the GCM projects increases in extremes even when the projected change in the mean was a decrease: but this was not always true for the higher resolution models. Thus, while the higher resolution RCM climate projections often concur with the GCM projections, there are times and places where they differ significantly due to their better representation of physical processes. It should also be noted that the model resolution can modify precipitation characteristics beyond just its mean value.
\end{abstract}

KEY WORDS: Regional climate model · Model resolution · Southeast Australia · Weather Research and Forecasting $\cdot \mathrm{WRF} \cdot$ Precipitation

Resale or republication not permitted without written consent of the publisher

\section{INTRODUCTION}

Climate change impact and adaptation responses are required at regional to local scales to help inform planning and management of infrastructure, urban development, water and energy sectors, agricultural output and a range of other social and economic activities. The need for such information drives research efforts in climate downscaling, particularly in locations where local features, such as coastlines and mountains, are known to impact regional atmospheric circulation and climate. When these locations contain large human populations, the need for downscaling of climate projections to inform planning and management is even greater.

The Eastern Seaboard of Australia is one such region. A relatively narrow strip of lowlands nestled between the coast and the mountains, it is home to almost half the population of the country. The distance from coast to mountains is often $<100 \mathrm{~km}$, which is too 
short to be resolved by most global climate models (GCMs). The Eastern Seaboard's climate response to large scale ocean modes (such as El Niño-Southern Oscillation) also differs significantly from relationships found within the Murray and Darling basins: Australia's largest river basins, which lie inland of the mountain range (Murphy \& Timbal 2008, Risbey et al. 2009). The unique climate response observed for the coastal region, together with the relatively small scales that mark its domain, means that GCMs are generally unable to capture the Eastern Seaboard climate, and hence little confidence can be placed in their projections of future climate change for this region (IPCC 2007, Suppiah et al. 2007).

A number of previous studies have downscaled GCM climate simulations over southeast Australia (Whetton et al. 2001, Song et al. 2008, Timbal et al. 2009, Evans \& McCabe 2010, Liu \& Zuo 2012). These studies evaluated the downscaling performance broadly over the region, with only Timbal et al. (2009) specifically assessing a statistical method over the Eastern Seaboard. Evans \& McCabe (2010) evaluated the Weather Research and Forecasting (WRF) regional climate model ( $\mathrm{RCM}$ ) used here, at daily and longer time scales over the Murray and Darling basins, while Evans \& Westra (2012) investigated the diurnal performance. The model was found to perform well across all time scales, though some consistent biases were found in areas dominated by clay soils as a response to simplified soil physics and parameterisations (Liu et al. 2010). Over a domain similar to that used in the present study, Evans et al. (2012) evaluated the performance of a multi-physics ensemble of simulated east coast storm events, the results of which were used to inform the model physics combination employed in the current analysis. In contrast to the previous investigations identified above, the present study specifically focuses on the present day performance and future climate change simulated by an RCM over the Eastern Seaboard.

Other studies have investigated the RCM performance in regions with similar coastal and mountainous influences, such as Christensen et al. (1998) over Scandinavia and Önol (2012) over the eastern Mediterranean. Both studies found that higher spatial resolution improved the climate simulation in these topographically complicated coastal regions. It should be noted that while the resolutions used in these studies were $<20 \mathrm{~km}$, many RCM simulations are performed at coarser resolutions. At the moment, the largest regional climate downscaling effort is being undertaken under the auspices of the COordinated Regional climate Downscaling EXperiment
(CORDEX) (Giorgi et al. 2009) with a standard resolution for dynamical downscaling of $50 \mathrm{~km}$ : a higher resolution than is obtained by GCMs, but lower than may be necessary over complex terrain in order to capture land-atmosphere coupling processes (Evans et al. 2011).

When investigating climate change impacts on water resources, characteristics of precipitation other than just the mean climate are required. In addressing the impacts on flooding regimes for example, knowledge of extreme precipitation events is of primary concern. The importance of these characteristics and the potential for them to change due to global warming have been discussed by a number of other studies (Trenberth et al. 2003, Allan \& Soden 2008). While these changes have been assessed at GCM and/or RCM scales (e.g. Beniston et al. 2007, Kharin et al. 2007), the ability of resolution to modify the projected changes in these characteristics remains to be fully explored.

In this study, simulations for both present and future climate are performed over southeast Australia. The model performance is evaluated against available observations and future changes analysed with a focus on the Eastern Seaboard. The investigation is performed across multiple spatial scales, ranging from GCM $(\sim 250 \mathrm{~km})$ to CORDEX $(50 \mathrm{~km})$ to high resolution $(10 \mathrm{~km})$, providing insight into 2 important research questions: (1) How does model resolution impact the simulation of the climate of the Eastern Seaboard and its projected future change? (2) How does model resolution impact projected changes in the characteristics of extreme precipitation?

\section{REGIONAL CLIMATE MODEL}

The WRF modelling system is developed as a collaborative partnership between a wide range of institutions and is maintained and distributed through the National Center for Atmospheric Research (NCAR). The version used in this study is the Advanced Research WRF (ARW) version 3.1.1 (Skamarock et al. 2008). WRF was run over southeastern Australia from 1985 through 2100, excluding the first 2 mo of the simulation, which were discarded as model spin-up.

The model used the following physics schemes: WRF Single Moment 5-class microphysics scheme; the Rapid Radiative Transfer Model (RRTM) longwave radiation scheme; the Dudhia shortwave radiation scheme; Monin-Obukhov surface layer similarity; Noah land-surface scheme; the Yonsei University boundary layer scheme; and the Kain-Fritsch cumu- 
lus physics scheme. These physics schemes have previously been shown to perform well over this domain (Evans \& McCabe 2010). The deep soil temperature was allowed to vary slowly with a $150 \mathrm{~d}$ lagged averaging period, while the atmospheric $\mathrm{CO}_{2}$ concentration changed monthly following values used in the GCM simulation.

The model simulation uses 6 hourly boundary conditions from the CSIRO Mk3.5 GCM simulation in the CMIP3 archive. This GCM (Gordon et al. 2002) was run using $\mathrm{T} 63$ resolution $\left(\mathrm{Ca} .2^{\circ} \times 2^{\circ}\right.$ ) with 18 vertical levels on hybrid sigma-pressure levels. Conditions from 1985 through 2000 derive from the 20th century simulation, while after 2000 the SRES A2 emission scenario simulation is used. WRF is run with 2 domains that are one-way nested: an outer $50 \mathrm{~km}$ resolution nest $(42 \times 45$ grid points $)$ and an inner $10 \mathrm{~km}$ resolution nest $(156 \times 186$ grid points) that covers southeastern Australia (Fig. 1). The outer 5 rows/ columns are a linear relaxation zone for the boundary conditions. Both nests use 30 vertical levels spaced more closely together within the planetary boundary layer.

Fig. 1 shows southeast Australia as dominated by large, relatively flat areas. Clearly visible in the WRF10 topography are the mountain range in the western part of the domain and the long mountain range near the east coast of Australia, with the highest peaks in the southern region of the Murray basin. The GCM is unable to resolve terrain features such as the western mountains and has only a very broad representation of the mountain range near the east coast. In Australia, these topographic features have considerable influence on the regional scale hydrometeorology, representing a distinct boundary between the wetter coastal fringe (Eastern Seaboard) and the drier interior.

Each of the regions shown in Fig. 1 differ in their overall change in topography with resolution. The smallest change occurs in the Darling basin, with most of the basin being relatively flat and the mountains to the north and east being relatively small to mid-sized. The Murray basin has larger topographic changes than the Darling basin, with relatively flat areas but also the largest mountains in the region occurring in the east of this basin. The Eastern Seaboard presents the largest changes, with the GCM simulation having just 1 or 2 grid points in the east-west direction. At higher resolutions the presence of small coastal plains and steep mountain slopes becomes apparent, with some locations transitioning from ocean to mountain peak in only a few $10 \mathrm{~s}$ of $\mathrm{km}$.

\section{RESULTS}

Throughout the rest of the paper, the CSIROMk3.5 GCM simulation will be referred to as GCM, the WRF $50 \mathrm{~km}$ resolution simulation will be referred to as WRF50, and the WRF $10 \mathrm{~km}$ resolution simulation will be referred to as WRF10. Thus, due to nesting of the models, WRF50 refers to the results

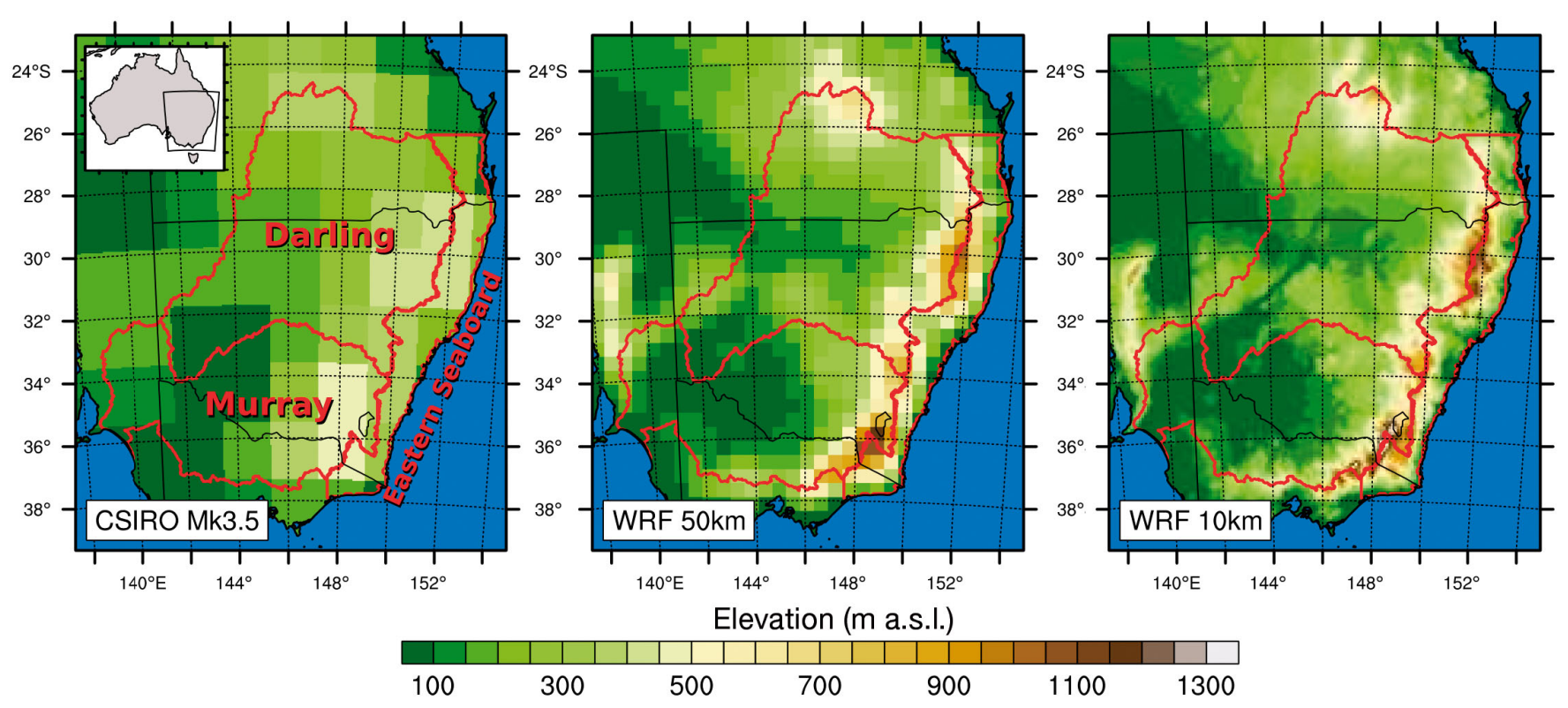

Fig. 1. Model topography from the CSIRO Mk3.5 GCM ( 250 km resolution) and WRF at 50 and $10 \mathrm{~km}$ resolution. Red outline: Darling river basin, Murray river basin and Eastern Seaboard 
from the GCM + WRF50 simulation while WRF10 refers to the results from the GCM + WRF50 + WRF10 simulation.

\subsection{Present climate evaluation}

The climate simulations are evaluated against the gridded observational dataset produced as part of the Australian Water Availability Project (AWAP) (Jones et al. 2009). This dataset uses over 6000 precipitation stations and 700 temperature stations to produce gridded products at a $0.05 \times 0.05^{\circ}$ spatial resolution. The AWAP data set uses smoothing splines to grid the climatological values and the Barnes successivecorrection method to apply anomaly fields to the climatology. Comparisons with these observations are made over a $25 \mathrm{yr}$ period from 1985 through 2009.

The spatial distribution of mean seasonal temperature is shown in Fig. 2. The figure clearly reflects the close relationship between elevation and temperature and shows that the higher resolution is better able to capture the elevation-related temperature changes in the mountain range along the east coast. The GCM has a temperature minimum in the southeast (in winter-June to August, JJA), coincident with its highest topography $(\sim 500 \mathrm{~m})$. This region reaches $\sim 1200 \mathrm{~m}$ at $50 \mathrm{~km}$ resolution, and $>1400 \mathrm{~m}$ at $10 \mathrm{~km}$ resolution. As a consequence, the higher resolution simulations are much better able to reproduce the observed spatial distribution of temperature within these regions.

The GCM is also warmer in areas with relatively small elevation changes. This is most readily observed in the northwest of the domain during spring and summer (SON [September to November] and DJF [December to February], respectively), where the GCM is as much as $4^{\circ} \mathrm{C}$ warmer than the AWAP observations. The higher resolution simulations are not able to correct for this warm bias and actually increase the bias in this region in line with the bias found in Evans \& McCabe (2010), where WRF was driven by reanalysis. WRF10 reduces the area affected compared to WRF50, but still remains warmer than the GCM over significant areas. Thus this warm bias is partially due to WRF and may be related to deficiencies in the treatment of clay soils under very dry conditions (Liu et al. 2010).

The mean monthly bias, root mean square error (RMSE), and pattern correlation (see Evans \& McCabe 2010 for definitions) for mean temperature are shown in Fig. 3. All statistics were calculated by first interpolating the models and observations to the
WRF10 grid. In the Murray basin, WRF50 has a similar bias to the GCM from February to July, but smaller biases during the rest of the year. WRF10 has smaller biases than WRF50 all year, except for June when it has a slightly larger negative bias. In the Darling basin, WRF10 has the same or smaller biases than the GCM for all months except February to May, while WRF50 has slightly higher biases throughout the year. On the Eastern Seaboard, WRF50 has smaller bias than the GCM in all months except June \& July, while WRF10 has a smaller bias throughout the year.

The differences in bias are also reflected in the RMSE, except along the Eastern Seaboard, where a clear reduction in RMSE is seen throughout the year as resolution improves. In terms of pattern correlation, improvements are seen throughout the year for all regions as resolution increases, with the main improvement occurring between the GCM and WRF50 and a relatively minor improvement from WRF50 to WRF10.

These statistics provide a consistent and robust picture of simulation improvements with resolution on the Eastern Seaboard, where the combination of coastlines and mountains play a strong role in the regional climate. Often the largest improvements are seen between the GCM and WRF50, with a small additional improvement obtained when moving to WRF10.

Within the Murray basin, the first half of the year (January to June) presents little improvement between WRF50 and the GCM simulation. During the second half of the year (July to December) however, large improvements in model performance with resolution are observed. As with the eastern seaboard response, the increased resolution of the WRF10 simulation provides an incremental improvement throughout the year compared to WRF50. These results reflect the influence of the high mountains in the east on the climate of the Murray basin. In the Darling basin, where the change in topography is smallest, the statistics show a mixed response to increasing resolution.

Given the critical importance of precipitation in this semi-arid basin, an assessment on the seasonal representation of the spatial distribution of rainfall across the domain is presented in Fig. 4 for each simulation. As can be seen, the GCM is unable to capture any semblance of the precipitation maxima over the mountains in the southeast. Furthermore, the GCM generally underestimates precipitation throughout the domain, except in summer (DJF) when it captures the observed maxima on the northeast coast. Rain 

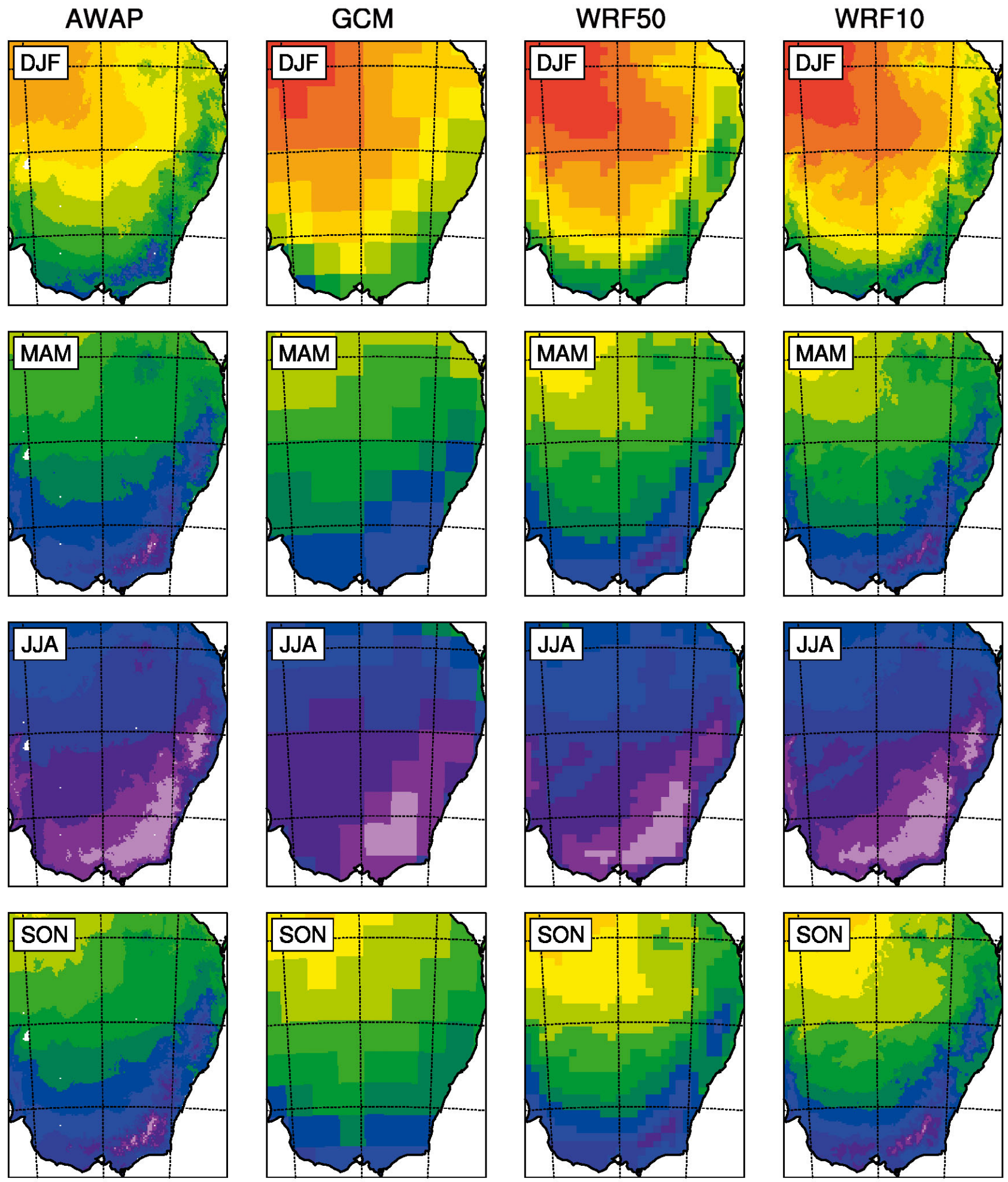

Temperature $\left({ }^{\circ} \mathrm{C}\right)$

\section{$\begin{array}{lllllllllllllll}8 & 10 & 12 & 14 & 16 & 18 & 20 & 22 & 24 & 26 & 28 & 30 & 32 & 34 & 36\end{array}$}

Fig. 2. Mean seasonal temperature (1985-2009) from Australian Water Availability Project (AWAP) observations and the global (GCM) and regional (Weather Research and Forecasting, WRF) climate models. WRF resolutions: 50 and 10 km. DJF: Dec-Feb, MAM: Mar-May, JJA: Jun-Aug, SON: Sep-Nov 

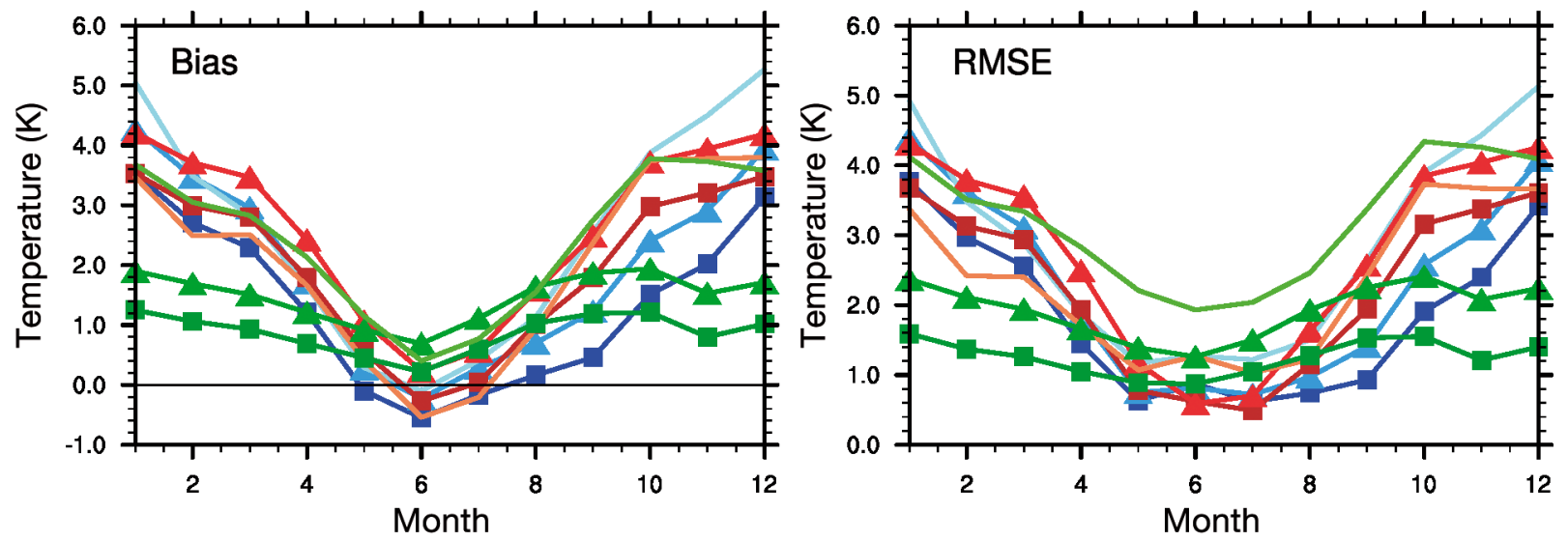

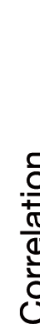

Fig. 3. Monthly mean temperature statistics for the Murray basin, Darling basin and Eastern Seaboard (ES), compared to AWAP observations
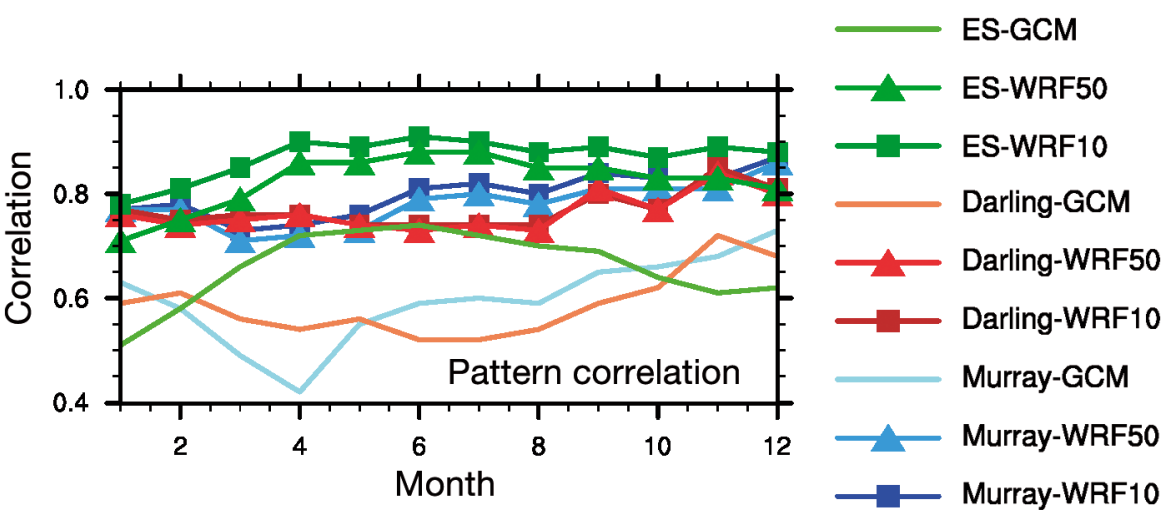

from this maxima does, however, extend further inland than in the observations. In contrast, the higher resolution simulations are better able to capture the maxima associated with the mountains in the southeast, and are generally better at reproducing rainfall patterns along the east coast. During summer however, the WRF runs tend to overestimate the precipitation on the east coast, and produce too much rain extending inland across the northern tier of the domain.

Mean monthly statistics for the reproduction of precipitation by the models are shown in Fig. 5. In the Murray basin, a fairly consistent improvement in bias with resolution is seen for most of the year, while in the Darling basin, little change in bias accompanies the change in resolution. On the Eastern Seaboard, an improvement in bias with increasing resolution is seen for most of the year except for December to March, when the higher resolutions produce higher rainfall overestimates. In terms of the RMSE, the WRF models generally do better than the GCM in the Murray basin, though WRF10 does not clearly improve relative to WRF50. On the Eastern Seaboard, the WRF models outperform the GCM from April through November, but not during the rest of the year when their bias is high. While WRF10 performs slightly better than WRF50 during the low bias period, it performs worse during the high bias period. The pattern correlation in the Murray basin and Eastern Seaboard shows a general improvement with increasing resolution, with most of this improvement occurring between the GCM and WRF50. In the Darling basin there is little change with resolution.

This evaluation shows an improvement in the simulation of precipitation when comparing the WRF simulations to the GCM. The improvement is relatively small in the Darling basin, quite consistent throughout the year in the Murray basin, and is present on the Eastern Seaboard for all periods except in the summer months (DJF), when the WRF models exhibit a large overestimation of precipitation. As for the comparison against observed temperature, most of the statistical improvements occur between the GCM and WRF50 simulations, with WRF10 providing an incremental improvement over WRF50.

Overall, the evaluation results indicate that the WRF simulations do improve upon the performance of the GCM, with much of this improvement captured by WRF50 and a smaller additional improvement obtained with WRF10. The largest changes are generally observed along the Eastern Seaboard, followed by the Murray basin and the Darling basin: as expected, based upon the change in topography. The 

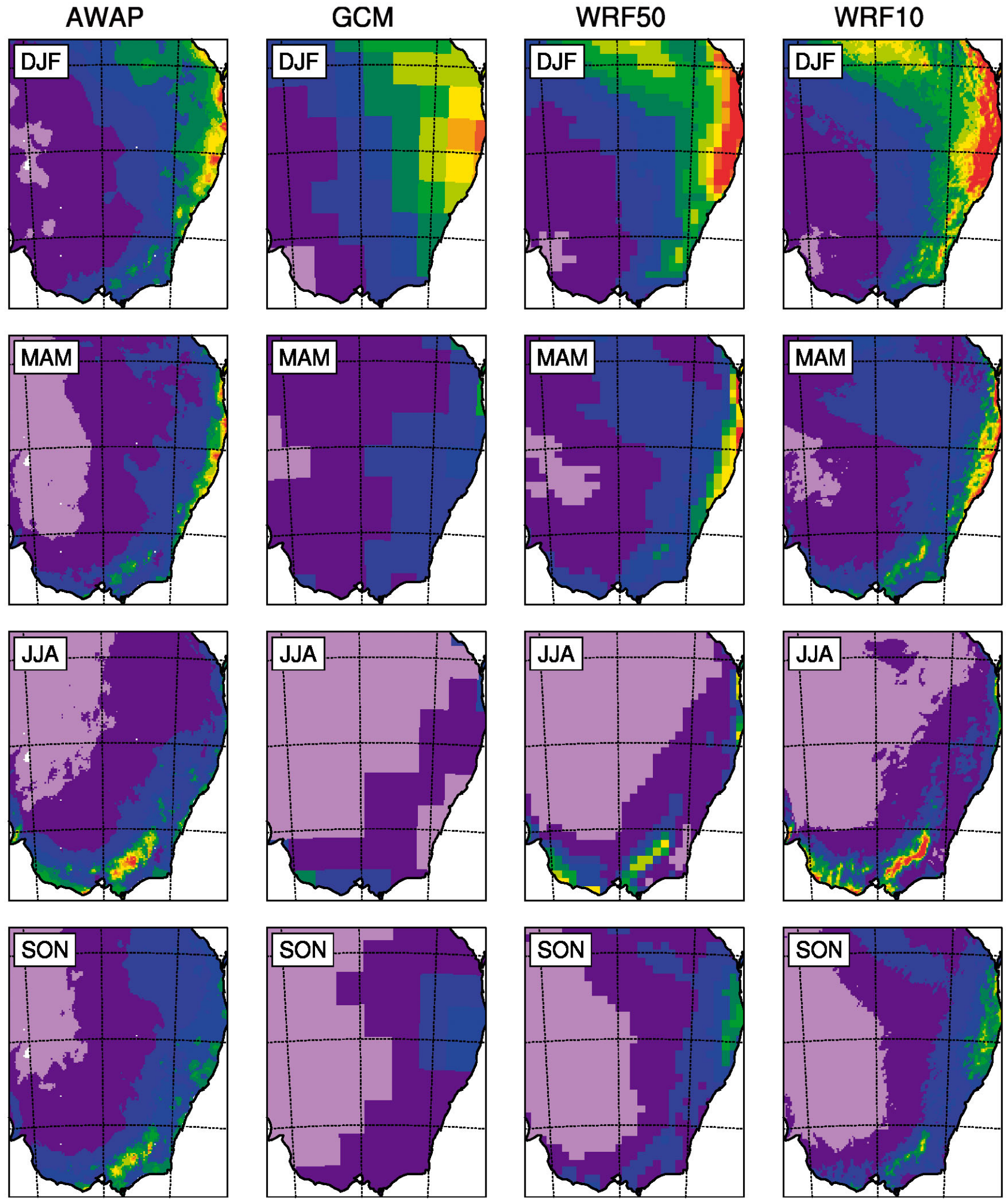

Precipitation $\left(\mathrm{mm} \mathrm{mo}^{-1}\right)$

$\begin{array}{llllllllll}20 & 40 & 60 & 80 & 100 & 120 & 140 & 160 & 180 & 200\end{array}$

Fig. 4. Mean seasonal precipitation (1985-2009) from AWAP observations and models. See Fig. 2 for details 

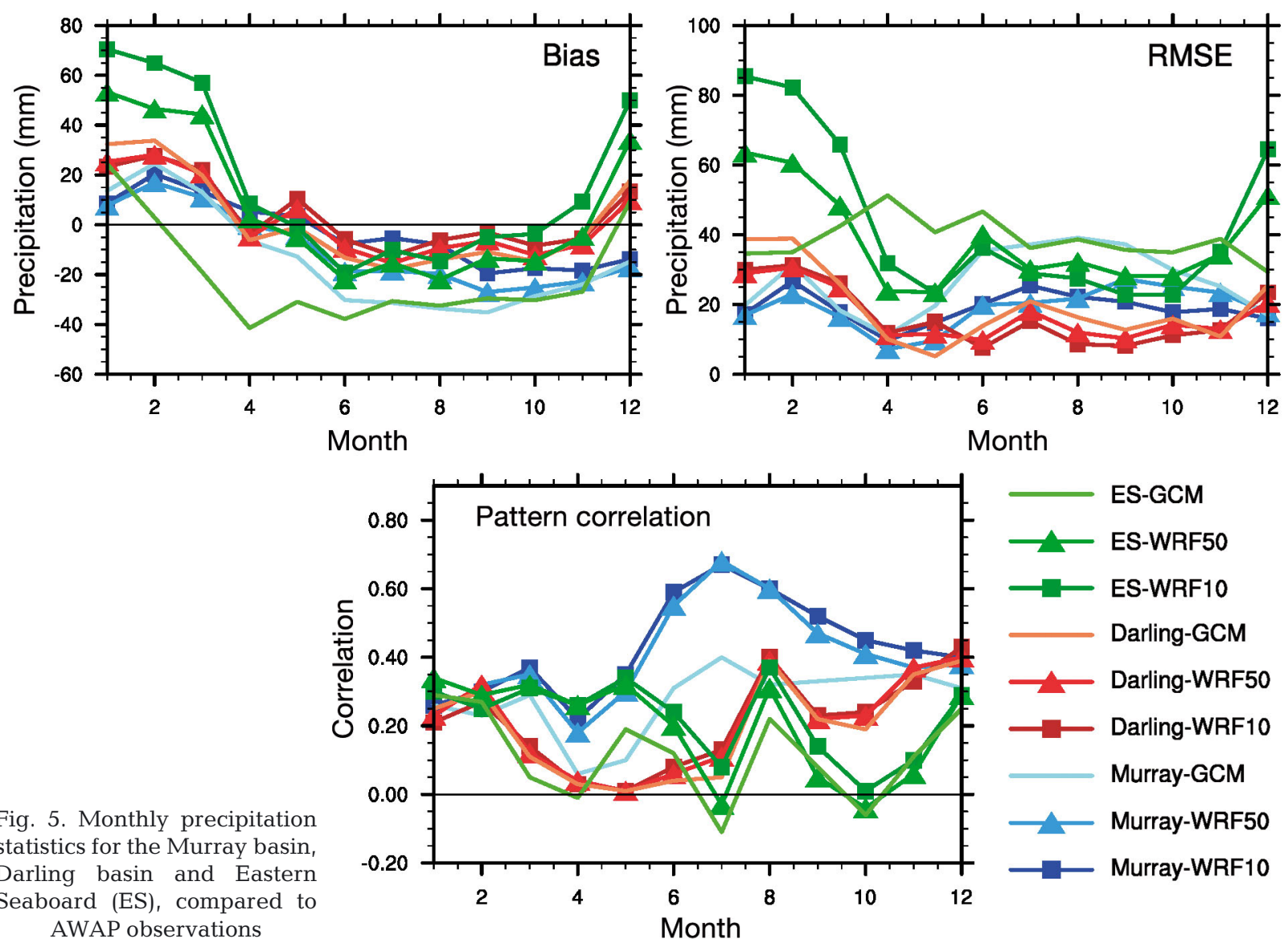

Fig. 5. Monthly precipitation statistics for the Murray basin Darling basin and Eastern Seaboard (ES), compared to AWAP observations

improvements in temperature are more consistent than the improvements in precipitation, which reflects the more direct relationship that exists between temperature and elevation than between precipitation and elevation.

\subsection{Future projections}

While examining the fidelity of present day simulations is a critical step in evaluating the hydrometeorological performance of these schemes, understanding the development of future atmospheric conditions is one of the key motivations of this work. Here we examine whether the projected climate changes vary when employing different model resolutions. That is, while using higher resolution generally improves the simulation of regional climate, does it affect the climate changes projected to occur in a globally warmed future? It should be recalled that each higher resolution uses boundary conditions derived from the resolution below it, such that the same large scale forcing is propagated through the WRF lateral boundaries in each case.
Fig. 6 shows the change in mean seasonal temperature taken as the 25 yr mean from 2075 to 2099 minus the 25 yr mean from 1985 to 2009. While the overall patterns of warming are similar between resolutions, some distinctions can be made. In summer, higher resolutions produce stronger warming, with large areas warming $\sim 0.5^{\circ} \mathrm{C}$ more in WRF10 than in the GCM. Higher resolutions also have a clear signal of less warming along the coastal strip. WRF10 also has larger warming in the mountains in the southeast than is present at lower resolutions. WRF10 tends to produce more warming than WRF50 overall, while both produce less warming than the GCM (except in summer).

These changes are reflected in Fig. 7, where the mean warming is shown for the minimum and maximum temperatures separately. For minimum temperature, the 2 WRF simulations project a very similar change that is systematically lower in spring (September to November, SON) than the change predicted by the GCM. For maximum temperature, higher resolution results in larger temperature increases in summer, but produces mixed results for other seasons. In the Murray basin, WRF50 projects 

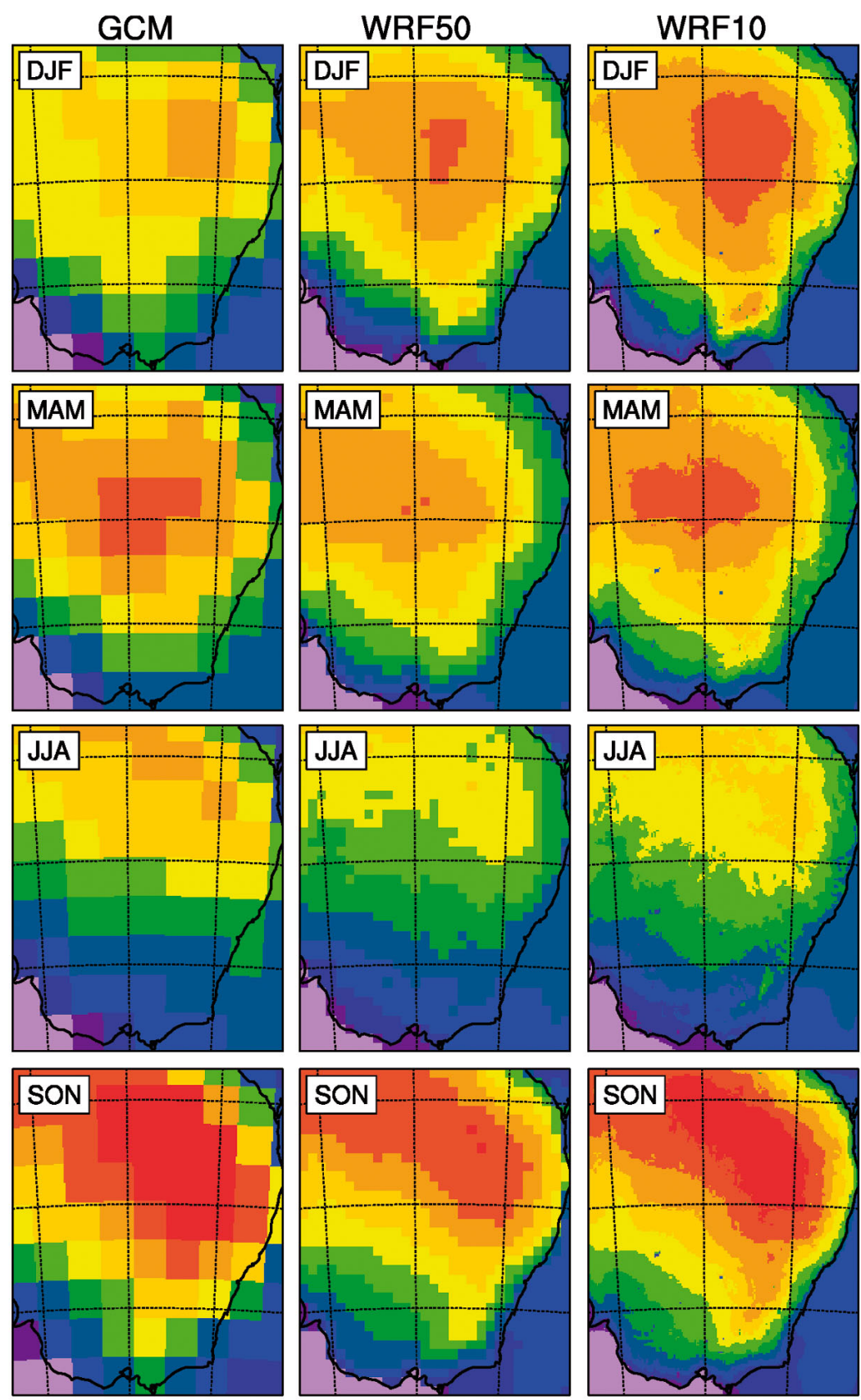

$\Delta$ Temperature $\left({ }^{\circ} \mathrm{C}\right)$

$\begin{array}{lllllllllll}2.5 & 2.75 & 3 & 3.25 & 3.5 & 3.75 & 4 & 4.25 & 4.5 & 4.75 & 5\end{array}$

Fig. 6. Spatial change in mean seasonal temperature for each model. Each panel: 2075-2099 mean minus 1985-2009 mean. See Fig. 2 for abbreviations

very similar changes to the GCM outside summer, while WRF10 projects consistently larger increases of $\sim 0.25^{\circ} \mathrm{C}$. In the Darling basin, WRF10 projects very similar changes to the GCM except for summer, while WRF50 projects consistently smaller increases, again of $\sim 0.25^{\circ} \mathrm{C}$. On the Eastern Seaboard, the WRF simulations project similar changes that are $\sim 0.5^{\circ} \mathrm{C}$ lower than the GCM in autumn (March to May, MAM) and winter (June to August, JJA).

Fig. 8 highlights the projected change in mean seasonal precipitation between the two 25 yr periods. The hue of the colour represents the change in $\mathrm{mm} \mathrm{mo}^{-1}$, while the saturation/ intensity of the colour represents the change in percent of the 1985-2009 mean value. The largest precipitation increases are projected in summer (DJF), although only patches of these increases represent $>25 \%$ of present day values. Significant areas also show very little change. In winter and spring, most of the region is projected to experience decreases of $>25 \%$, although this often represents a decrease of $<10 \mathrm{~mm} \mathrm{mo}^{-1}$.

Some significant differences between resolutions can be seen in Fig. 8. In absolute amounts, the GCM projects an increase in the east in summer, a decrease in the Darling basin in autumn and spring, and little change in winter. WRF50 enhances the summer increase in the east, slightly increases the Darling basin decrease in autumn and produces an increase along the east coast that is not present in the GCM. In winter, WRF50 produces a decrease in the mountains in the southeast (which also occurs in autumn and spring) and along the southwest coast, while in spring it produces a smaller decrease in the Darling basin than the GCM. WRF10 displays similar changes to those seen in WRF50, but with more spatial structure and often larger maximums. For example, the precipitation decrease over the southeast mountains is considerably larger in WRF10, the east coast precipitation in Autumn is stronger (though the maxima occur off-shore) and the area of increase in summer has considerably more structure, almost splitting into 2 distinct maxima: one west of the mountains and the other east.

The mean seasonal precipitation changes for each of the areas of interest are shown in Fig. 9. While the 

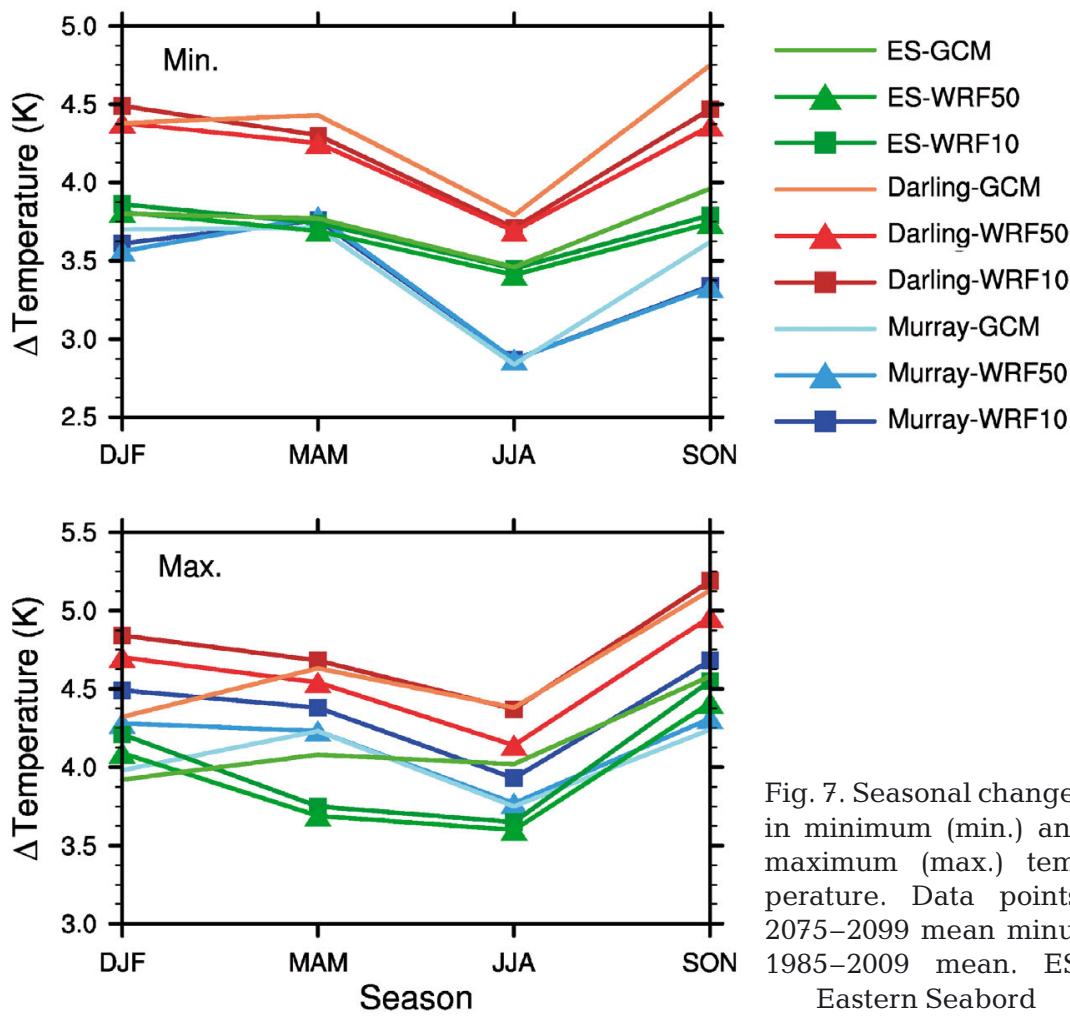

Fig. 7. Seasonal changes in minimum (min.) and maximum (max.) temperature. Data points: 2075-2099 mean minus 1985-2009 mean. ES:

Eastern Seabord

also examined. These changes are quantified using the climate change indices R95pTOT and R99pTOT as defined by the Expert Team on Climate Change Detection and Indices (ETCCDI, http://etccdi.pacificclimate. org/index.shtml) (Peterson 2005). These indices are the annual total precipitation when the daily precipitation is above the 95th and 99th percentiles respectively. These changes, expressed as a percentage of the 1985-2009 value and averaged over our areas of interest, are shown in Fig. 10. It should be noted that the 95th percentile events are large events that generally occur many times per year, while the 99th percentile events are rarer more extreme events that may only occur a few times per year.

In the Murray basin, where a consistent decrease in precipitation occurs, the WRF simulations produce a decrease in the R95pTOT and almost no change in the R99pTOT. In con-

absolute changes occur over a similar range of increases and decreases, the percent decreases are much larger than the percent increases. This demonstrates that the increases tend to occur at times and places of large present day precipitation, while the decreases often occur at times and places with relatively small present day precipitation. Similar absolute changes are projected in the Darling basin at all resolutions except in autumn, when higher resolutions project a larger decrease in precipitation. In the Murray basin, WRF50 projects similar absolute changes to the GCM, while WRF10 projects consistently larger decreases in all seasons. This difference occurs almost entirely over the highest mountains in the southeast. Since the terrain in this area is much better represented at higher resolution, providing a better representation of the local climate, it could be argued that there is greater confidence in the higher resolution projections here, keeping in mind that this result is from a single GCM/RCM pair. On the Eastern Seaboard, WRF50 projects larger absolute increases (or smaller decreases) than the GCM in summer, autumn and winter. WRF10 projects consistently smaller increases (and larger decreases) than does the WRF50 simulation.

As well as understanding how model resolution can modify projected mean climate changes, the impact on extreme precipitation characteristics are trast, the GCM projection produces little change in R95pTOT but a $35 \%$ increase in R99pTOT. Thus, even while decreasing precipitation overall, the GCM increases the total precipitation contributed by the extreme events. A similar result for the GCM can also be seen in the Darling basin, where an overall decrease of precipitation is also projected. In this case, all models project a small decrease in the large events but an increase in the extreme events. On the Eastern Seaboard, increases in large and extreme events dominate at all resolutions. These increases occur predominantly in summer, with small winter decreases.

\section{DISCUSSION}

Similar to a number of previous studies, we find an overall improvement in the simulation of local climate when using higher resolution models in regions with significant topography and coastlines (Evans 2010, Prömmel et al. 2010, Feser et al. 2011, Di Luca et al. 2012, Önol 2012, Tselioudis et al. 2012). While not all changes are improvements, the climate of the Murray basin and the Eastern Seaboard are better represented at high resolution, while the Darling basin shows relatively little sensitivity to resolution. This result agrees with the potential added value of 

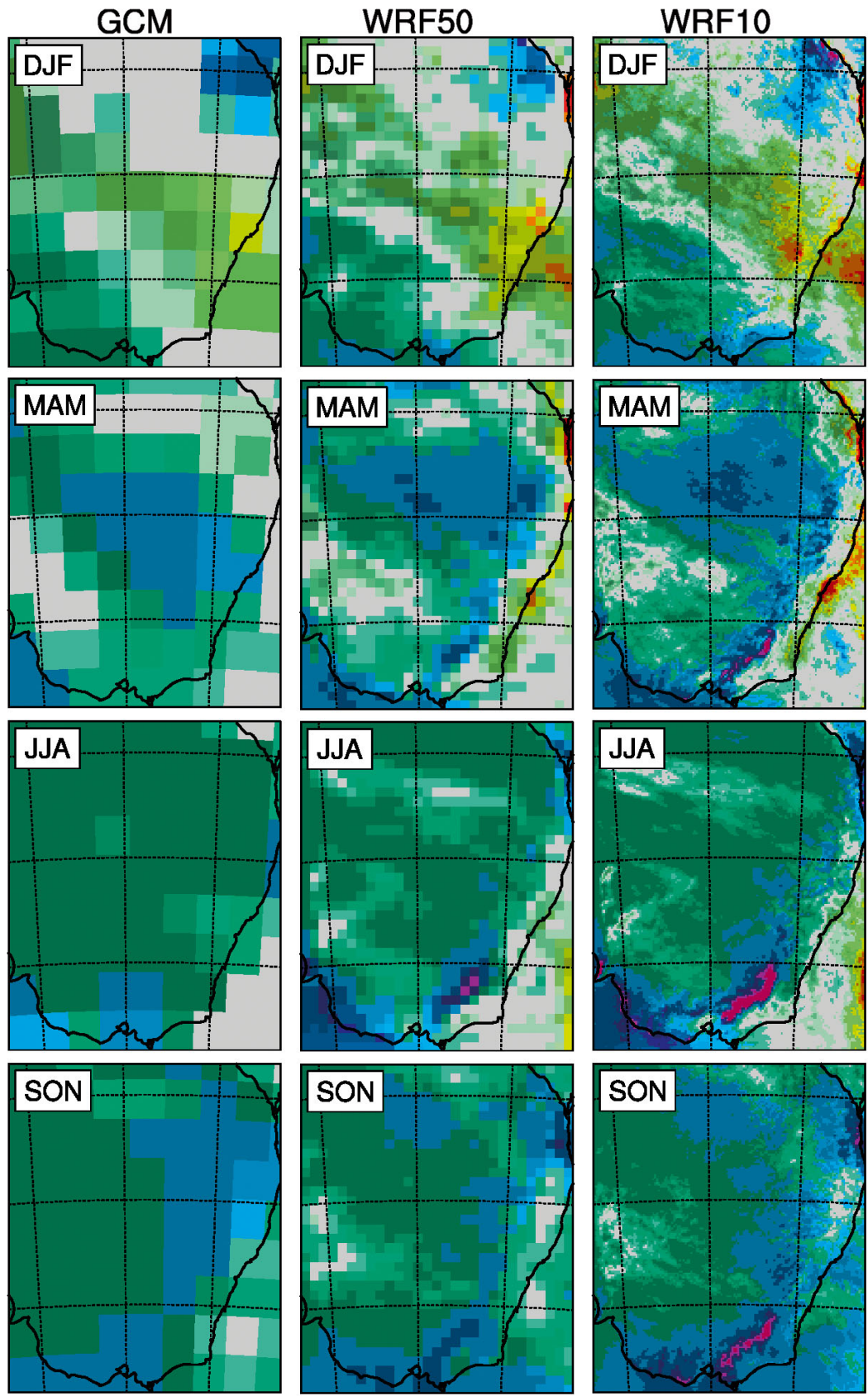

$\Delta$ Precipitation $\left(\mathrm{mm} \mathrm{mo}^{-1}\right)$

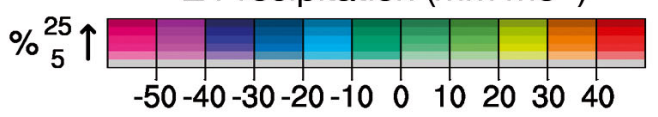

Fig. 8. Spatial change in seasonal precipitation. Each panel: 2075-2099 mean minus 1985-2009 mean. Hue: change in $\mathrm{mm} \mathrm{mo}^{-1}$; saturation: change in \% from grey $(<5 \%$ change with respect to 1985-2009 mean value regardless of absolute volume of change) to darkest hues (>25\% change)

regional climate modelling discussed in Di Luca et al. (2012), even taking into account that results have been averaged seasonally, which reduces the impact of using higher spatial resolution.
The improvement in temperature correlates well with improvements in topography and coastline representation. The influence of the coastline and topography is clearly seen in the precipitation (Fig. 4). While the precipitation field is generally improved, a large overestimation of summer precipitation is generated over the Eastern Seaboard. These biases can be compared to those shown in Evans \& McCabe (2010) where WRF is driven by reanalysis. In both cases, WRF increases the precipitation along the coast and in the mountains in the southeast, as well as across the north during spring (SON). The strong increase in precipitation on the northeast coast in summer (DJF) is not present when WRF is driven by reanalysis, suggesting that this might be caused by the GCM driving conditions. During summer in this region, the GCM has a tendency to transport tropical air to higher latitudes than occurs in the reanalysis, and into the WRF domain through the northeast quadrant of the boundary (Fig. 11). While water vapour generally exits the domain through this boundary, the reanalysis does bring water vapour into the domain during summer. The GCM tends to exaggerate these inflow events to such an extent that the long-term summer average changes from a net outflow in the reanalysis, to a net inflow in the GCM. This is consistent with Colman et al. (2011), who found that GCMs tended to transport tropical moisture, and precipitation, too far south over Australia in summer. With this warm moist air, the low topography of the GCM is sufficient to generate precipitation comparable to that observed. However, when the same air-mass is driven over the higher topography of the WRF simulations, significantly more precipitation is generated, clearly showing the impact that an error in the GCM circulation can have on the regional model climate. This also suggests that 

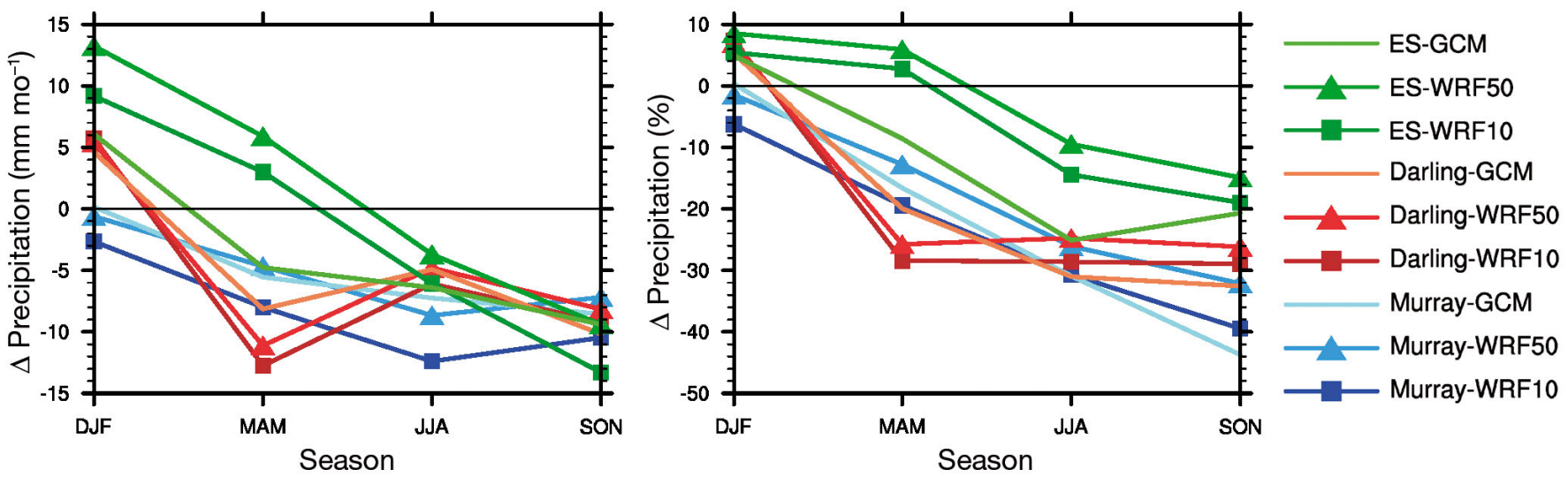

Fig. 9. Seasonal changes in precipitation. Data points: 2075-2099 mean minus 1985-2009 mean. ES: Eastern Seabord
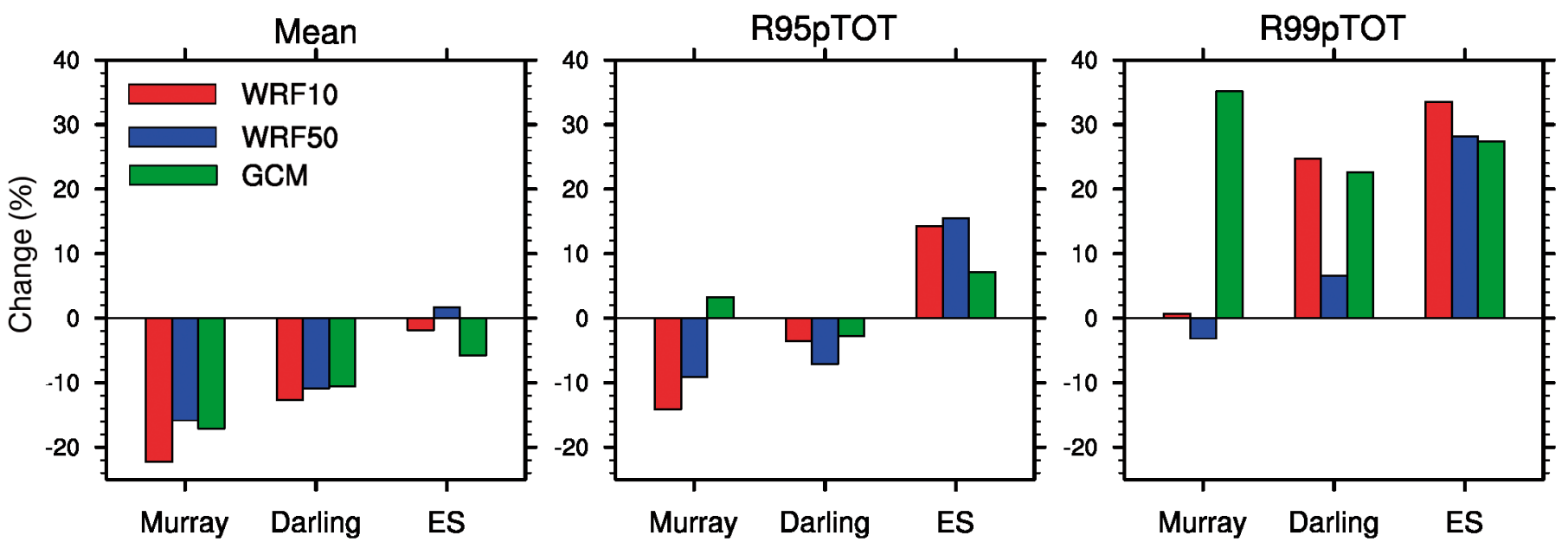

Fig. 10. Change in mean and extreme precipitation indices R95pTOT and R99pTOT. Change is calculated as 2075-2099 minus 1985-2009. ES: Eastern Seabord

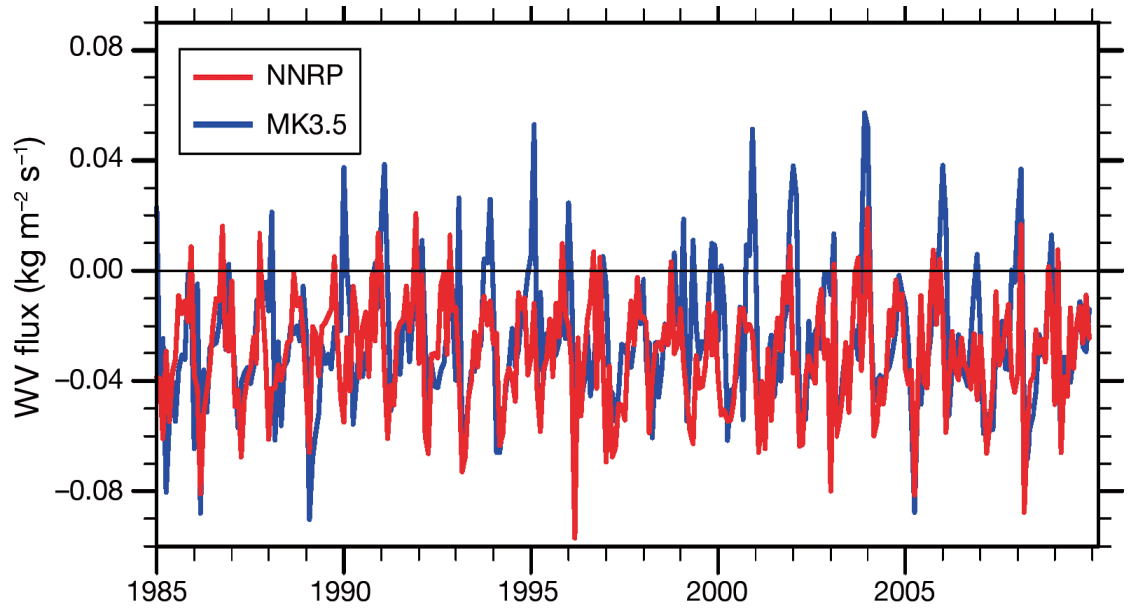

Fig. 11. Monthly water vapour (WV) flux into the domain through the northeast quadrant of the boundary as simulated by the NCEP/NCAR Reanalysis project (NNRP) and the CSIRO-MK3.5 GCM when evaluating GCMs in order to choose appropriate boundary conditions for downscaling to regional climate, the use of surface variables, such as precipitation, may be insufficient.

While both WRF50 and WRF10 produce higher precipitation due to this high moisture influx interacting with the topography, WRF10 consistently produces smaller increases (or larger decreases) in precipitation in the future. In both cases, over the Eastern Seaboard, future winds contain stronger easterly components. This shift of precipitation upwind may be due to the larger coastal mountains in WRF10 more effectively blocking 
low-level easterly flows. This would cause incoming air masses to begin to rise further from the mountains and as a result, rain that fell on-shore at lower resolutions would now fall off-shore. Such a mechanism has been found in both theoretical (Jiang 2003) and observational studies (Bousquet \& Smull 2003) of orographic precipitation. Thus, while the higher topography induced by the higher resolution does produce more orography related precipitation overall, the proximity to the coast means that upstream blocking can force this precipitation off-shore and reverse the expected resolution-precipitation relationship.

When investigating the difference in future climate projections due to resolution changes, we find the largest differences in those regions where the largest effect was observed in the present day comparison: the Eastern Seaboard and the Murray basin. These changes can be strong enough to convert a precipitation decrease in the GCM into an increase at higher resolution, as occurs in autumn on the Eastern Seaboard. Similar impacts of resolution were found in Tselioudis et al. (2012), where the higher resolution model produced an increase in precipitation that was not present in the driving GCM over Greece. They attribute much of this impact to the influence of higher topography, which appears to play an important role here as well.

The projected change in maximum temperature is 4 to $5 \mathrm{~K}$, depending on the region (Fig. 7), and the impact of using higher resolution is $\sim 0.5 \mathrm{~K}$, which is $\sim 10 \%$ of the total projected change. Hence, the higher resolution modelling does not substantively change the GCM projected future temperature. This $0.5 \mathrm{~K}$ resolution impact can also be compared to the range of temperature changes projected by GCMs in the CMIP3 ensemble (IPCC 2007, Suppiah et al. 2007, Perkins \& Pitman 2009) over southeast Australia, which range from $\sim 2.5$ to $4 \mathrm{~K}$. That is, the impact of higher resolution on projected temperature is equivalent to a third of the total range of future temperature changes projected by CMIP3 GCMs.

In terms of precipitation changes, it can be seen that higher resolution can produce changes that are more than double those projected by the driving GCM (Fig. 9) and may also be of opposite sign. The projected changes vary substantially by region and season, and include changes that vary from approximately -70 to $+10 \%$. Considering the difference between the RCMs projected change and the GCMs projected change in terms of the GCMs projected change, we see that the higher resolution can impact the projected change by as much as $\pm 20 \%$. This com- pares to CMIP3 ensemble changes that vary from approximately -80 to $+55 \%$ in this region (Suppiah et al. 2007). Hence, the impact of higher resolution on the projected precipitation change is equivalent to $30 \%$ of the range of future precipitation changes projected by the CMIP3 ensemble. While this result is derived from a single GCM and a single RCM, it suggests that the impact of dynamic downscaling on projected climate changes is comparable, though somewhat smaller, to the spread in large multi-model GCM ensembles.

Changes in GCM precipitation extremes in this region have been examined in Pitman \& Perkins (2008). They found a similar decrease in total rain over the Murray basin as this study, but an increase in extremes. Thus, the GCM follows previously identified behaviour of extremes increasing, even while the mean precipitation is decreasing. The higher resolution simulations however, project the precipitation extremes to remain essentially unchanged in the Murray basin. This difference between resolutions occurs in summer, when the GCM projects an increase in large and extreme events, but the higher resolution simulations project a decrease. This differs from the Darling basin where all resolutions generally agree on the changes in precipitation. Seasonally, there is an increase in both large (R95pTOT) and extreme (R99pTOT) events in summer. The summer increase in large events is counteracted by decreases in the other seasons. Little change occurs in the extreme events for seasons other than summer, allowing the summer increase to dominate. Thus, for this GCM-RCM combination, when changes in the mean and extreme precipitation are of opposite sign in the $\mathrm{GCM}$, the impact of resolution cannot be determined a priori.

\section{CONCLUSIONS}

To investigate the impact of resolution on the simulation of regional climate and climate change, a range of model resolutions spanning GCMs $(\sim 250 \mathrm{~km})$, CORDEX $(50 \mathrm{~km})$ and high resolution RCMs $(10 \mathrm{~km})$ were run across the southeast of Australia: an area that includes coastlines and mountain ranges. While this study examines results from a single GCM-RCM combination, many of the conclusions are likely applicable to other combinations as well. Overall, the mean regional climate was simulated better at higher resolution, with the largest differences between resolutions occurring where the mountains and coastlines play important climatological roles. In many 
cases, most of the improvement was realised at the $50 \mathrm{~km}$ resolution, with smaller improvements occurring when using higher resolution. This should give confidence to the users of CORDEX that results are relatively robust to resolution changes. It should be noted though, that this conclusion is based upon the temporal and spatial resolution of assessment, which for the current analysis, was monthly and seasonal over large watershed sized regions. Examining the impacts of higher spatial resolution simulations at shorter temporal scales is the focus of ongoing efforts.

It should also be noted that the RCMs were unable to correct for errors in the large scale forcing from the GCM. In this case, the GCM erroneously transported too much tropical moisture into the domain through the northeast quadrant of the boundary. With the low topography in the GCM, this extra moisture was enough to produce precipitation comparable to the observations, such that no error was seen in the precipitation field. At higher resolutions and with better resolved topography, this extra moisture manifests as too much precipitation compared to the observations, and highlights an error in the GCM circulation that would otherwise go unnoticed. This is an example of the GCM obtaining good results for the wrong reasons, which is often the case when models are able to reproduce observations despite not (or under) representing important physical processes. It can also be considered an example of the 'garbage in, garbage out' issue (Giorgi \& Mearns 1999), where the 'garbage in' went largely unnoticed until it was emphasised by the 'garbage out'.

In terms of the projected changes, the largest differences between resolutions were observed in precipitation over the regions influenced by mountains and coastlines. Over the Eastern Seaboard in particular, a higher resolution was able to change the sign of the projected change during autumn. For this region, it was found that the higher resolution topography was able to more effectively block low-level easterly flows, which are often associated with coastal precipitation. At $10 \mathrm{~km}$ resolution, this blocking is effective enough to cause upstream lifting and precipitation to occur further from the mountains. The proximity of the mountains to the coastline results in much of this precipitation occurring offshore, effectively reducing any precipitation increase on-shore. This mechanism provides an important link between the height of a mountain range, the distance to the coast, and the resolution of the model. While this physical mechanism is an event based phenomena, it occurs frequently enough to have cli- matological impacts for this region. This situation suggests that modelling with higher resolution has the potential to provide more added value on seasonal time scales than suggested in Di Luca et al. (2012).

In terms of precipitation extremes, the GCM has a tendency to project increases in extremes even when the mean is projected to decrease. This tendency is less pronounced in the higher resolution models. In the Murray basin, where a decrease in precipitation is consistently projected across seasons and resolutions, the higher resolution models project no change in extreme precipitation, whereas the GCM projects an increase of $35 \%$. This suggests that if GCMs project consistent decreases in mean precipitation, but increases in extremes, it would be worth testing this with higher resolution models before investing in impact assessments and adaptation responses.

While in many cases the climate changes projected using high resolution RCMs concur with those projected by GCMs, there are times and places where significant differences can occur. Mountains and coastlines are good examples of locations where resolution is important in order to accurately simulate a regions climate. The close proximity of mountains to coastlines adds complexity to this relationship, as the climatic effects of physical processes such as mountain blocking of low-level winds can reverse sign as resolution increases. It should also be noted that resolution can change aspects of the climate beyond the mean, such as precipitation extremes, which are important in impact and adaptation research.

Acknowledgements. This work has been funded by the Australian Research Council as part of the Discovery Project DP0772665 and Future Fellowship FT110100576. This work was supported by an award under the Merit Allocation Scheme on the NCI National Facility at the Australian National University.

\section{LITERATURE CITED}

Allan RP, Soden BJ (2008) Atmospheric warming and the amplification of precipitation extremes. Science 321: 1481-1484

> Beniston M, Stephenson DB, Christensen OB, Ferro CAT and others (2007) Future extreme events in European climate: an exploration of regional climate model projections. Clim Change 81:71-95

Bousquet O, Smull BF (2003) Observations and impacts of upstream blocking during a widespread orographic precipitation event. Q J R Meteorol Soc 129:391-409

Christensen OB, Christensen JH, Machenhauer B, Botzet M (1998) Very high-resolution regional climate simulations over Scandinavia - present climate. J Clim 11: 3204-3229 
Colman RA, Moise AF, Hanson LI (2011) Tropical Australian climate and the Australian monsoon as simulated by 23 CMIP3 models. J Geophys Res 116:D10116

Di Luca A, de Elía R, Laprise R (2012) Potential for added value in precipitation simulated by high-resolution nested Regional Climate Models and observations. Clim Dyn 38:1229-1247

Evans JP (2010) Global warming impact on the dominant precipitation processes in the Middle East. Theor Appl Climatol 99:389-402

Evans JP, McCabe MF (2010) Regional climate simulation over Australia's Murray-Darling basin: a multitemporal assessment. J Geophys Res 115:D14114, doi:10.1029/ 2010JD013816

Evans J, Westra S (2012) Investigating the mechanisms of diurnal rainfall variability using a Regional Climate Model. J Clim 25(20):7232-7247

Evans JP, Ekström M, Ji F (2012) Evaluating the performance of a WRF physics ensemble over South-East Australia. Clim Dyn 39:1241-1258

Evans JP, Pitman AJ, Cruz FT (2011) Coupled atmospheric and land surface dynamics over southeast Australia: a review, analysis and identification of future research priorities. Int J Climatol 31:1758-1772

Feser F, Rrockel B, Storch H, Winterfeldt J, Zahn M (2011) Regional climate models add value to global model data: a review and selected examples. Bull Am Meteorol Soc 92:1181-1192

Giorgi F, Mearns LO (1999) Introduction to special section: regional climate modeling revisited. J Geogr Res 104: 6335-6352

Giorgi F, Jones C, Asrar GR (2009) Addressing climate information needs at the regional level: the CORDEX framework. WMO Bull 58:175-183

Gordon HB, Rotstayn LD, McGregor JL, Dix MR and others (2002) The CSIRO Mk3 Climate System Model. CSIRO Atmospheric Research, Aspendale

IPCC (2007) Climate change 2007: the physical science basis. Solomon S, Qin D, Manning M, Chen Z and others (eds) Cambridge University Press, Cambridge

Jiang Q (2003) Moist dynamics and orographic precipitation. Tellus A 55:301-316

Jones DA, Wang W, Fawcett R (2009) High-quality spatial climate data-sets for Australia. Aust Meteorol Mag 58: 233-248

Kharin VV, Zwiers FW, Zhang X, Hegerl GC (2007) Changes in temperature and precipitation extremes in the IPCC ensemble of global coupled model simulations. J Clim 20:1419-1444

Liu DL, Zuo H (2012) Statistical downscaling of daily climate variables for climate change impact assessment over New South Wales, Australia. Clim Change 115(3-4):629-666

Editorial responsibility: Filippo Giorgi,

Trieste, Italy
Liu YY, Evans JP, McCabe MF, De Jeu RAM, Van Dijk AIJM, Su H (2010) Influence of cracking clays on satellite estimated and model simulated soil moisture. Hydrol Earth Syst Sci 14:979-990

Murphy B, Timbal B (2008) A review of recent climate variability and climate change in southeastern Australia. Int J Climatol 28:859-879

Önol B (2012) Effects of coastal topography on climate: highresolution simulation with a regional climate model. Clim Res 52:159-174

Perkins SE, Pitman AJ (2009) Do weak AR4 models bias projections of future climate changes over Australia? Clim Change 93:527-558

Peterson TC (2005) Climate Change Indices. WMO Bull 54: 83-86

Pitman AJ, Perkins SE (2008) Regional projections of future seasonal and annual changes in rainfall and temperature over Australia based on skill-selected AR4 models. Earth Interact 12:1-50

Prömmel K, Geyer B, Jones JM, Widmann M (2010) Evaluation of the skill and added value of a reanalysis-driven regional simulation for Alpine temperature. Int J Climatol 30:760-773

Risbey JS, Pook MJ, McIntosh PC, Wheeler MC, Hendon $\mathrm{HH}$ (2009) On the remote drivers of rainfall variability in Australia. Mon Weather Rev 137:3233-3253

Skamarock WC, Klemp JB, Dudhia J, Gill DO and others (2008) A description of the advanced research WRF Version 3. NCAR, Boulder, CO

Song R, Gao X, Zhang H, Moise A (2008) $20 \mathrm{~km}$ resolution regional climate model experiments over Australia: experimental design and simulations of current climate. Aust Meteorol Mag 57:175-193

Suppiah R, Hennessy K, Whetton PH, McInnes K and others (2007) Australian climate change projections derived from simulations performed for the IPCC 4th Assessment Report. Aust Meteorol Mag 56:131-152

> Timbal B, Fernandez E, Li Z (2009) Generalization of a statistical downscaling model to provide local climate change projections for Australia. Environ Model Softw 24:341-358

Trenberth KE, Dai A, Rasmussen RM, Parsons DB (2003) The changing character of precipitation. Bull Am Meteorol Soc 84:1205-1217

> Tselioudis G, Douvis C, Zerefos C (2012) Does dynamical downscaling introduce novel information in climate model simulations of precipitation change over a complex topography region? Int J Climatol 32:1572-1578

Whetton PH, Katzfey JJ, Hennessy KJ, Wu X, McGregor JL, Nguyen K (2001) Developing scenarios of climate change for Southeastern Australia: an example using regional climate model output. Clim Res 16:181-201

Submitted: September 17, 2012; Accepted: January 15, 2013 Proofs received from author(s): March 12, 2013 